\title{
Hematopoietic Growth Factors in the Management of Anemia and Febrile Neutropenia
}

\author{
Hartmut Link \\ Kaiserslautern, Germany
}

Keywords

G-CSF · Febrile neutropenia · Chemotherapy-induced anemia Epoetin $\cdot$ Erythropoietin

\begin{abstract}
Chemotherapy-induced anemia (CIA) in cancer patients correlates with poor performance status and decreased quality of life. Currently recommended causal therapies are erythropoiesis-stimulating agents (epoetins), iron substitution, or a combination of both. Guidelines recommend considering red blood cell (RBC) transfusions for symptomatic anemia at a hemoglobin $(\mathrm{Hb})$ level of $<8 \mathrm{~g} / \mathrm{dl}$. Granulocyte colony-stimulating factor (G-CSF) is recommended if the risk of febrile neutropenia (FN) following from the chosen chemotherapy protocol is $\geq 20 \%$. If a chemotherapy is planned that induces a moderate $\mathrm{FN}$ risk (10-20\%), the individual overall FN risk should be assessed prior to each chemotherapy cycle, taking into account patient- or tumor-related risk factors. G-CSF is required when risk factors such as age $\geq 65$ years, advanced disease or relevant comorbidity, or previous neutropenia complications are present. Neutropenia that required a shift in chemotherapy is also an indication for G-CSF prophylaxis in subsequent cycles, in order to maintain the planned dose intensity. The use of G-CSF improves patient survival and reduces the rate of neutropenia complications.
\end{abstract}

C 2019 S. Karger AG, Basel

\section{KARGER}

๑ 2019 S. Karger AG, Basel

\section{Granulocyte Colony-Stimulating Factors}

The goals of chemotherapy in patients with cancer are cure, prolongation of survival, and alleviation of symptoms caused by the disease. Results of scientific clinical studies with proven positive results are decisive for the selection of chemotherapy protocols. This results in a standard therapy if the study results have been evaluated and recommended accordingly by professional associations, such as the German Cancer Society, Onkopedia, the European Society for Medical Oncology (ESMO), the National Comprehensive Cancer Network (NCCN), the American Society of Clinical Oncology (ASCO), and others. The medical doctors obtain their information via the protocols from the original publications, via compendia published by experts, or online from databases such as Onkopti ${ }^{\circledR}$ (www.onkopti.de) and others. The results were obtained with cytostatic drugs, dosages, and time intervals specified in the studies; i.e., these then define the standard of therapy. The cytostatic dosage used per time unit of the protocol thus corresponds to the standard dose intensity. Dose reductions or interval extensions reduce the dose intensity. If, for example, the dose intensity of adjuvant CMF chemotherapy (cyclophosphamide, methotrexate, 5 -fluorouracil) in patients with breast cancer is less than $85 \%$, the survival of the patients is significantly worse or the same as in the control group without chemotherapy [1]. Comparable results were also published for other diseases. 
Many cytotoxic substances impair the formation of blood cells from pluripotent hematopoietic stem cells in the bone marrow and, in particular, the granulopoiesis from which the neutrophil granulocytes develop. As the most important dose-limiting toxicity, neutropenia, febrile neutropenia (FN), and infections can compromise the success of chemotherapy by risk of death and the resulting reduced dose intensity of chemotherapy. Patients with severe neutropenia lack the typical inflammatory signs of an infection due to the neutrophil deficiency. Fever is therefore the first and often the only sign of infection. Since the patients are immunosuppressed as a result of chemotherapy, an infection spreads in the organism within a few hours and can lead to death.

Infections are the most common causes of death in cancer patients as a result of therapy. The risk of FN or life-threatening infections correlates with the severity and duration of the neutropenia [2]. The risk of infection increases significantly below 1,000 neutrophils per microliter. Mortality from infections in chemotherapy-induced neutropenia is $2.8 \%$ and early mortality is $5.7 \%$ [3]. Data from care systems in the USA also confirmed the significantly increased mortality in FN in over 10,000 patients [4].

The first sign of infection in neutropenia is usually fever, as the only symptom (measured orally), with no identifiable cause, from $\geq 38.3$ or $\geq 38.0{ }^{\circ} \mathrm{C}$ for at least $1 \mathrm{~h}$, persisting or occurring twice within $12 \mathrm{~h}$. Fever in neutropenia must always be regarded as a life-threatening infection, which must be treated within $1 \mathrm{~h}$ with antibiotics in a standardized way $[5,6]$. The necessary diagnostics must not delay the therapy. The empirical therapy depends on the pathogens found in the case of proven infection, on the results of studies, and on the current pathogen and resistance situation, as well as on increasing multiresistance. In principle, the relevant Gram-negative and Gram-positive pathogens must be covered.

Not only increased costs but also the impairment of quality of life are further negative consequences of neutropenia complications.

Many therapy protocols can only achieve the required standard dose intensity if neutropenia and FN can be avoided or kept within a clinically acceptable range.

Among the most important determinants of FN risk are chemotherapy type and dose intensity. The risk of FN in most therapy regimens for the treatment of various frequent tumors is greater during the first therapy cycles than in the subsequent cycles [7]. This can be explained by the fact that, in the following cycles, often hematopoietic growth factors are used and the chemotherapy dose is reduced. Without such adjustment, the risk of FN during all cycles is constant [8]. If neutropenic complications occur, a high FN risk can also be assumed in the subsequent cycle.

\section{Prophylaxis of Neutropenia and of Febrile}

\section{Neutropenia}

Granulocyte formation is controlled by hematopoietic growth factors such as granulocyte colony-stimulating factor (G-CSF) or granulocyte/macrophage colony-stimulating factor (GM-CSF), which are released into the bloodstream as the granulocyte concentration decreases to stimulate proliferation or differentiation of progenitor cells. G-CSF was described and biochemically characterized in the early 1980s; the corresponding gene was cloned and developed as a recombinant molecule for clinical application in neutropenia [9].

The prophylactic administration of recombinant GCSF preparations such as filgrastim, lenograstim, pegfilgrastim, or lipegfilgrastim accelerates the regeneration of protective granulocyte cell counts after myelosuppressive chemotherapy. Many clinical trials have established the clinical usefulness of prophylactic G-CSF therapy following chemotherapy to shorten neutropenia $[9,10]$. It has convincingly been shown that the rate of FN, infections during neutropenia, and neutropenia-related mortality can be significantly reduced by the use of G-CSF [11].

Combination chemotherapy protocols increase the risk of FN compared to monotherapies, as well as drugs toxic to bone marrow or mucous membranes. Significant predictors of severe neutropenia or FN are high-dose cyclophosphamide or etoposide in the treatment of malignant lymphoma as well as high-dose anthracyclines in early breast cancer [12]. According to various guidelines, the intensity of the chemotherapy protocol correlates directly with the risk of FN. Besides the type of chemotherapy, there are patient- and tumor-specific factors influencing the risk of FN.

The German guideline Supportive Care 2016 and the ASCO, European Organisation for Research and Treatment of Cancer (EORTC), ESMO, and NCCN guidelines recommend primary G-CSF prophylaxis if the risk of FN is above $20 \%$ [13-17].

With an FN risk of 10-20\%, G-CSF prophylaxis is only indicated in case of additional risk factors. Age is a significant risk factor, so that G-CSF prophylaxis is always recommended for patients aged $\geq 65$ years if the FN risk is above $10 \%$.

Further risk factors are: poor performance status (Eastern Cooperative Oncology Group (ECOG) > 1), comorbidity (different definitions), past chemotherapy history, anemia (hemoglobin $(\mathrm{Hb})<12 \mathrm{~g} / \mathrm{dl}$ ), lymphocytopenia $(<700 / \mu \mathrm{l})$, hypalbuminemia $(<35 \mathrm{~g} / \mathrm{dl})$, and hyperbilirubinemia. In addition, previous radiotherapy appears to increase the risk of FN.

The algorithm for deciding on G-CSF prophylaxis is shown in figure 1 .

Information on the FN risk of chemotherapy protocols can be obtained from the guidelines of the EORTC, the 


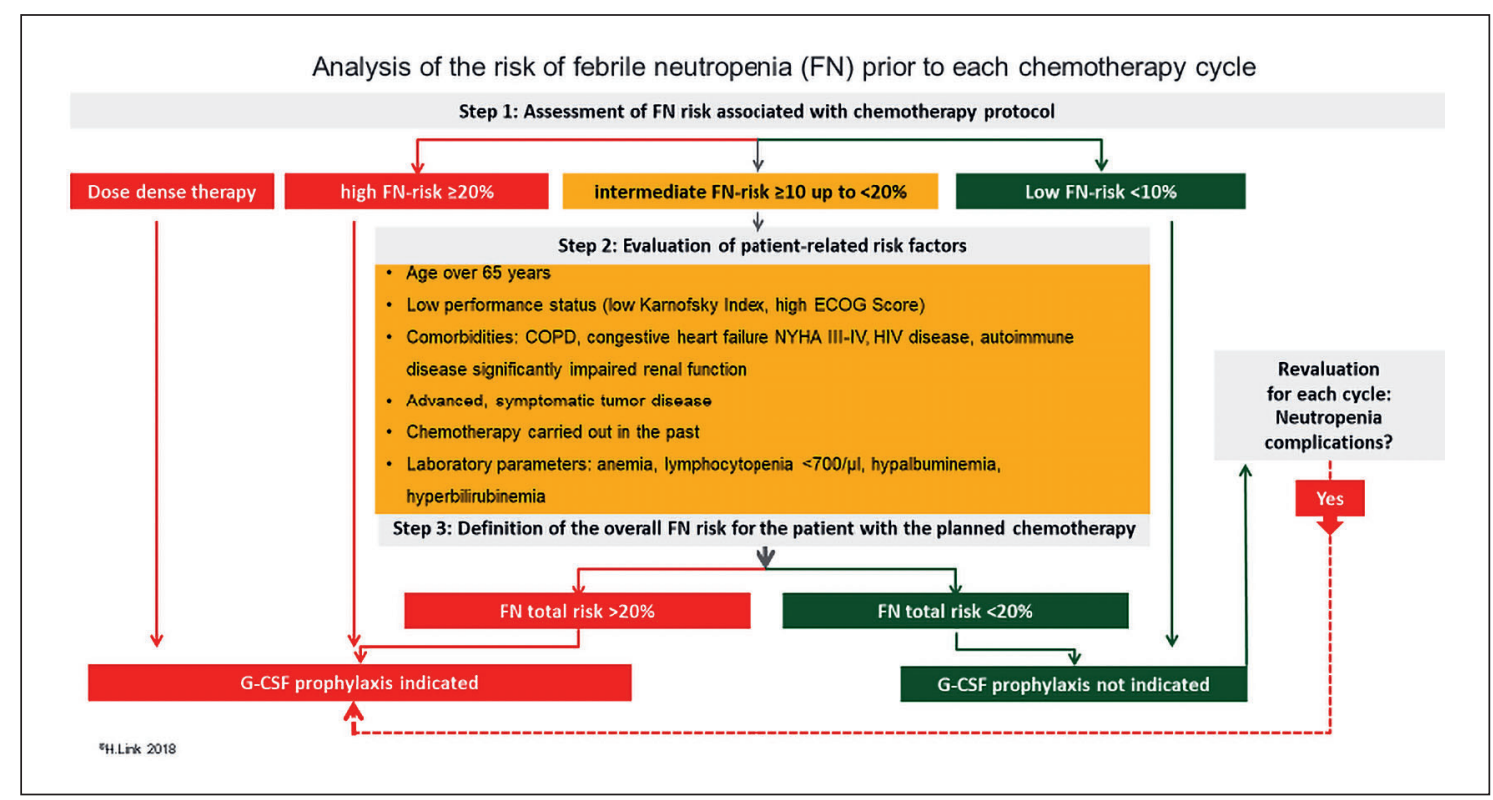

Fig. 1. Procedures for decision-making on G-CSF prophylaxis based on the guidelines [13-17].

NCCN, partly from the long version of the S3 guideline on supportive therapy, and from the Internet protocol database Onkopti (www.onkopti.de, December 10, 2018) $[13-15,17]$, and a recent paper on the G-CSF guideline adherence in Germany [18].

G-CSF may also be indicated for chemotherapy with an FN risk of less than $10 \%$. If a planned chemotherapy cycle has to be postponed due to neutropenia, G-CSF should be administered prophylactically, especially in the case of curative therapy intentions in the subsequent cycles, in order to better achieve the planned dose intensity.

Prophylactic G-CSF administration should take place, at the earliest, $24 \mathrm{~h}$ and no later than 3 days after completion of chemotherapy, unless the protocol explicitly states otherwise [15-17]. At a later start of therapy with filgrastim, the regeneration of neutrophils is delayed so that the desired clinical effect is lower [19].

If daily G-CSF is used, this should be done until the granulocytes normalize. This is certainly not always the case in the clinical routine so that, with the single administration of long-acting pegfilgrastim, a better protection of patients is possible [20,21].

A meta-analysis of randomized trials with G-CSF showed that the survival of patients with G-CSF prophylaxis is significantly higher than without prophylaxis, (p $<0.0001$ ) [22]; however, the rate of secondary malignancies was significantly higher.

The number of patients needed to treat to observe 1 secondary malignancy was $213(\mathrm{p}<0.00017)$ in all 25 studies used for secondary malignancy analysis. Since the number of patients who needed to be treated with G-CSF to avoid 1 death was 29 ( $\mathrm{p}<0.0001$ ), for every death avoided, 0.135 secondary malignancies occurred (data from all 25 studies) and for every secondary malignancy observed, 7.4 deaths were avoided (cited from [22]).

It could not be determined whether the risk of secondary malignancies was associated with the supportive use of G-CSF or with the leukemogenic effects of enhanced chemotherapeutic agents.

\section{Management of Anemia with Erythropoiesis- Stimulating Factors}

Several studies have shown that the quality of life of cancer patients with anemia is reduced [23, 24]. The causes of anemia are multifactorial, so that a diagnosis should always be made first, the results of which then determine the therapy.

In the vast majority of cases, tumor-related factors are responsible for the development of anemia. The specific tumor anemia is a paraneoplastic symptom, i.e., it arises from the effect of cytokines that are released as a reaction of the immune system to the malignant disease and which suppress erythropoiesis. The cytokine interleukin-6, which stimulates the production of the protein hepcidin in the liver, deserves special mentioning here. Hepcidin in turn inhibits the uptake of iron (also from iron tablets) from the duodenum and the release of iron from the stores of the reticuloendothelial system (RES) [25]. As a result, erythropoiesis has too little iron available, resulting in functional iron deficiency and anemia. This effect 
Fig. 2. ESMO guidelines regarding the management of chemotherapy-induced anemia in patients with solid or hematological malignancies. $\mathrm{Hb}=$ Hemoglobin, ID $=$ iron deficiency, i.v. $=$ intravenous, $\mathrm{RBC}=$ red blood cell, $\mathrm{SF}=$ serum ferritin, TSAT $=$ transferrin saturation, $\sqrt{ }=$ normal value). Modified from [27].

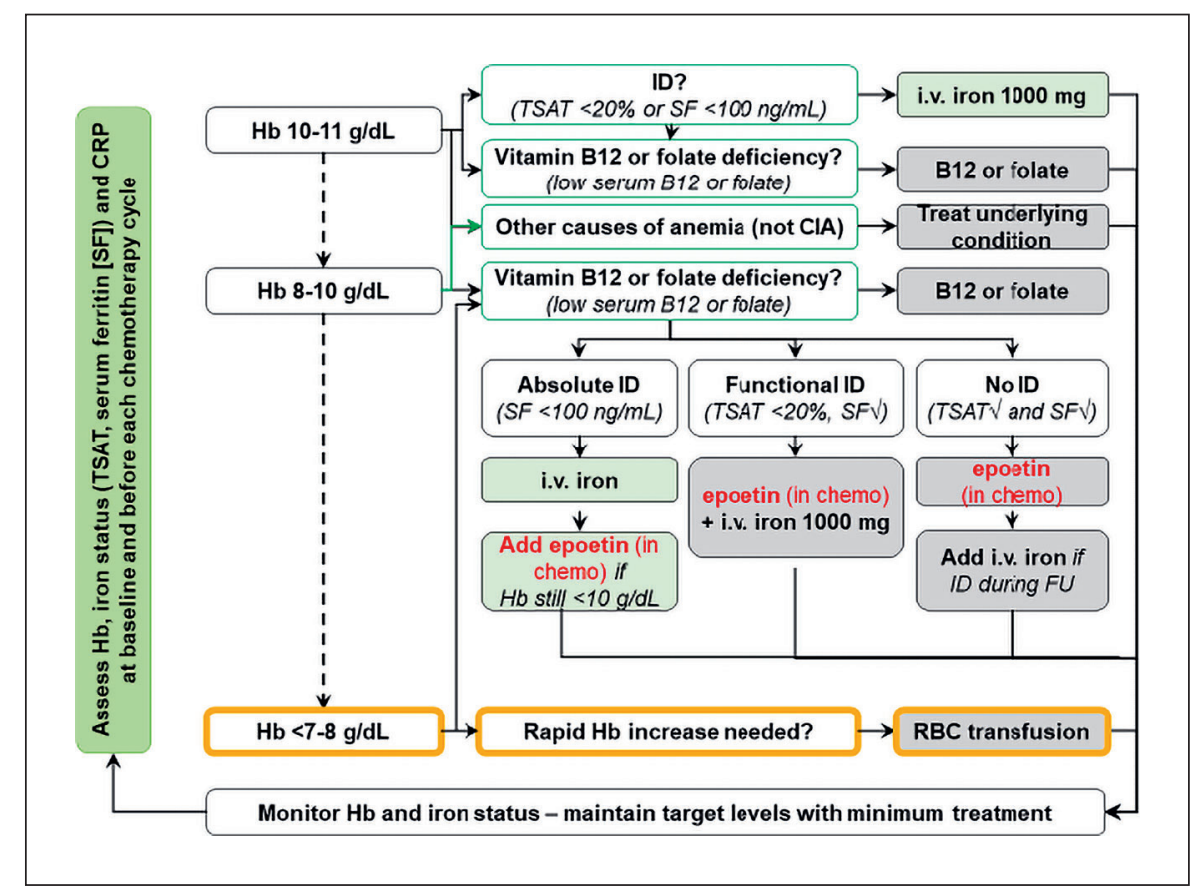

is also present in infections and autoimmune diseases. In summary, this form of anemia is referred to as 'anemia of chronic disease'.

In addition, many cytostatic drugs, tyrosine kinase inhibitors, and radiotherapy can cause anemia by inhibiting erythropoiesis and the formation of erythropoietin. In other respects, gastrointestinal bleeding, vitamin B12 deficiency, folic acid or absolute iron deficiency, and heavy alcohol consumption can lead to anemia. In many cases, several causes occur at the same time.

\section{Therapy of Anemia}

Therapy is required for clinical complaints or symptoms. In particular, age and accompanying diseases such as coronary heart disease must be taken into account. Of course, iron, folic acid, or vitamin B12 deficits must be substituted and further examined, depending on the situation.

In relation to the extent of the anemia, there are several treatment options. These are iron substitution and transfusions, as well as additional erythropoiesis-stimulating agents (epoetins) in tumor therapy-induced anemia [13, 25-27].

The discussion on the safety of epoetins and transfusions plays a central role in the individual choice of therapy for the treatment of anemia associated with tumors. Both lead to an increase in thromboembolic events. Among the risks described for red blood cell (RBC) transfusions were an increased mortality and complication rate as well as a higher tumor recurrence rate $[28,29]$. $\mathrm{RBC}$ transfusions should therefore be used as carefully as possible $[30,31]$.
In the past, increased mortality and the risk of tumor progression under anemia therapy with epoetins in tumor patients were discussed if their $\mathrm{Hb}$ values were raised to $>12 \mathrm{~g} / \mathrm{dl}(7.45 \mathrm{mmol} / \mathrm{l})$. However, the data on these side effects were inconsistent overall.

New meta-analysis results are now available showing that the benefit of epoetin exceeds the risk and that tumor progression is not increased when epoetins are used to treat chemotherapy-induced anemia according to German and international guidelines [13]. According to the current epoetin approval, studies on anemia caused by radiotherapy/radiochemotherapy and studies with epoetin administration at a $\mathrm{Hb}$ value $>10 \mathrm{~g} / \mathrm{dl}(6.2 \mathrm{mmol} / \mathrm{l})$ were excluded. Neither the mortality in the study period nor overall survival (OS) was found to be different. Thromboembolism (14 studies, relative risk (RR): 1.53 (1.02-2.31); $\mathrm{p}=0.04$; i.e., 12 more thromboembolic events in 1,000 patients under epoetin than in the control arm) and hypertension (14 studies, $\mathrm{n}=2,564$; RR: 2.05 (1.32$3.18) ; p=0.001$ ) occurred more frequently. Similar data for patients with breast cancer have been published [32]. A prospective comparative study in metastatic breast cancer after chemotherapy also showed no clinically relevant difference in patient survival [33].

The aim of epoetin therapy is to reduce anemia symptoms and thus improve the quality of life, to reduce the number of transfusions required and to achieve an $\mathrm{Hb}$ value of at most $12 \mathrm{~g} / \mathrm{dl}(7.5 \mathrm{mmol} / \mathrm{l})$. The dosages and therapy intervals are based on the recommendations of the various manufacturers. Fixed doses of epoetin- $\alpha$ $(40,000 \mathrm{U} /$ week), epoetin- $\beta 30,000 \mathrm{U} /$ week, epoetin- $\theta$ 
(20,000 U/week), or darbepoetin- $\alpha(2.25 \mu \mathrm{g} / \mathrm{kg} /$ week or $500 \mu \mathrm{g} / 3$ weeks) are recommended. A higher dosage (doubling) in case of non-response $(<1 \mathrm{~g} / \mathrm{dl}(0.62 \mathrm{mmol} / \mathrm{l}))$ after 4 weeks is only clinically investigated and useful in epoetin-theta. Therapy should be discontinued after 6-8 weeks in the case of non-response and 4 weeks after the end of chemotherapy in the case of response.

The additional intravenous (i.v.) iron therapy in oncological patients leads to significantly greater $\mathrm{Hb}$ increases than therapy with epoetin alone or with additional oral iron (which is usually ineffective) [25, 34].

\section{Conclusion}

The hematopoietic growth factors G-CSF and epoetin are standard in supportive therapy and should be used for the benefit of patients according to the guidelines. The ESMO guidelines on anemia treatment and the use of epoetins are summarized in figure 2 [27].

\section{Disclosure Statement}

There was no sponsorship or funding arrangement relating to this work. H.L. has received research grants or speaker's honoraria from and serves on the advisory boards of Accord, Amgen, Hexal-Sandoz, Janssen Cilag, Novartis, Teva, and Vifor Pharma.

\section{References}

-1 Bonadonna G, Valagussa P, Moliterni A, Zambetti M, Brambilla C: Adjuvant cyclophosphamide, methotrexate, and fluorouracil in node-positive breast cancer: the results of 20 years of follow-up. N Engl J Med 1995;332: 901-906.

2 Bodey GP, Buckley M, Sathe YS, Freireich EJ: Quantitative relationships between circulating leukocytes and infection in patients with acute leukemia. Ann Intern Med 1966;64: 328-340.

3 Kuderer NM, Dale DC, Crawford J, Lyman GH: Impact of primary prophylaxis with granulocyte colony-stimulating factor on febrile neutropenia and mortality in adult cancer patients receiving chemotherapy: a systematic review. J Clin Oncol 2007;25:31583167.

-4 Lyman GH, Michels SL, Reynolds MW, Barron R, Tomic KS, Yu J: Risk of mortality in patients with cancer who experience febrile neutropenia. Cancer 2010;116:5555-5563.

5 Heinz WJ, Buchheidt D, Christopeit M, von Lilienfeld-Toal M, Cornely OA, Einsele H, Karthaus M, Link H, Mahlberg R, Neumann S, Ostermann H, Penack O, Ruhnke M, Sandherr M, Schiel X, Vehreschild JJ, Weissinger F, Maschmeyer G: Diagnosis and empirical treatment of fever of unknown origin (FUO) in adult neutropenic patients: guidelines of the Infectious Diseases Working Party (AGIHO) of the German Society of Hematology and Medical Oncology (DGHO). Ann Hematol 2017;96:1775-1792.

-6 Taplitz RA, Kennedy EB, Bow EJ, Crews J, Gleason C, Hawley DK, Langston AA, Nastoupil LJ, Rajotte M, Rolston K, Strasfeld L, Flowers CR: Outpatient management of fever and neutropenia in adults treated for malignancy: American Society of Clinical Oncology and Infectious Diseases Society of America clinical practice guideline update. J Clin Oncol 2018;36:1443-1453.

-7 Crawford J, Dale DC, Kuderer NM, Culakova E, Poniewierski MS, Wolff D, Lyman GH: Risk and timing of neutropenic events in adult cancer patients receiving chemotherapy: the results of a prospective nationwide study of oncology practice. J Natl Compr Canc Netw 2008;6:109-118.

$\checkmark 8$ Chouaid C, Bassinet L, Fuhrman C, Monnet I, Housset B: Routine use of granulocyte colony-stimulating factor is not cost-effective and does not increase patient comfort in the treatment of small-cell lung cancer: an analysis using a Markov model. J Clin Oncol 1998; 16:2700-2707.

9 Welte K: G-CSF: filgrastim, lenograstim and biosimilars. Expert Opin Biol Ther 2014;14: 983-993.

10 Culakova E, Poniewierski MS, Wolff DA, Dale DC, Crawford J, Lyman GH: The impact of chemotherapy dose intensity and supportive care on the risk of febrile neutropenia in patients with early stage breast cancer: a prospective cohort study. Springerplus 2015;4: 396.

11 Bennett CL, Djulbegovic B, Norris LB, Armitage JO: Colony-stimulating factors for febrile neutropenia during cancer therapy. $\mathrm{N}$ Engl J Med 2013;368:1131-1139.

12 Fontanella C, Bolzonello S, Lederer B, Aprile G: Management of breast cancer patients with chemotherapy-induced neutropenia or febrile neutropenia. J Korean Med Sci 2014;9: 239-245.

13 Jordan K, Feyer P, Höller U, Link H, Wörmann B, Jahn F: Supportive treatments for patients with cancer. Dtsch Arztebl Int 2017; 114:481-487.

14 Smith TJ, Bohlke K, Lyman GH, Carson KR, Crawford J, Cross SJ, Goldberg JM, Khatcheressian JL, Leighl NB, Perkins CL, Somlo G, Wade JL, Wozniak AJ, Armitage JO: Recommendations for the use of WBC growth factors: American Society of Clinical Oncology clinical practice guideline update. J Clin Oncol 2015;33:3199-3212.

15 Aapro MS, Bohlius J, Cameron DA, Dal Lago L, Donnelly JP, Kearney N: 2010 update of EORTC guidelines for the use of granulocytecolony stimulating factor to reduce the incidence of chemotherapy-induced febrile neutropenia in adult patients with lymphoproliferative disorders and solid tumours. Eur J Cancer 2011;47:8-32.
16 Klastersky J, de Naurois J, Rolston K, Rapoport B, Maschmeyer G, Aapro M, Herrstedt J; ESMO Guidelines Committee: Management of febrile neutropaenia: ESMO clinical practice guidelines. Ann Oncol 2016;27:v111-v118.

17 Crawford J: NCCN ${ }^{\circledR}$ Practice Guidelines in Oncology - v.2.2018; Myeloid Growth Factors. 2018. www.nccn.org.

18 Link H, Kerkmann M, Holtmann L, Ortner P; Working Groups Supportive Care (ASORS now AGSMO) and Medical Oncology (AIO) within the German Cancer Society (DKG): GCSF guideline adherence in Germany, an update with a retrospective and representative sample survey. Support Care Cancer 2018;DOI: 10.1007/s00520-018-4481-x.

19 Crawford J, Kreisman H, Garewal H, Jones SE, Shoemaker D, Pupa MR, Armstrong S, Tomita D, Dziem G: The impact of filgrastim schedule variation on haematopoietic recovery post-chemotherapy. Ann Oncol 1997;8: 1117-1124.

20 Aapro M, Boccia R, Leonard R, Camps C, Campone M, Choquet S, Danova M, Glaspy J, Hus I, Link H, Sliwa T, Tesch H, Valero V: Refining the role of pegfilgrastim (a long-acting G-CSF) for prevention of chemotherapyinduced febrile neutropenia: consensus guidance recommendations. Support Care Cancer 2017;25:3295-3304.

21 Pfeil AM, Allcott K, Pettengell R, von Minckwitz G, Schwenkglenks M, Szabo Z: Efficacy, effectiveness and safety of long-acting granulocyte colony-stimulating factors for prophylaxis of chemotherapy-induced neutropenia in patients with cancer: a systematic review. Support Care Cancer 2015;23:525-545.

22 Lyman GH, Yau L, Nakov R, Krendyukov A: Overall survival and risk of second malignancies with cancer chemotherapy and G-CSF support. Ann Oncol 2018;29:1903-1910.

23 Littlewood TJ, Bajetta E, Nortier JW, Vercammen E, Rapoport B: Effects of epoetin alfa on hematologic parameters and quality of life in cancer patients receiving nonplatinum chemotherapy: results of a randomized, doubleblind, placebo-controlled trial. J Clin Oncol 2001;19:2865-2874. 
24 Witzig TE, Silberstein PT, Loprinzi CL, Sloan JA, Novotny PJ, Mailliard JA, Rowland KM, Alberts SR, Krook JE, Levitt R, Morton RF: Phase III, randomized, double-blind study of epoetin alfa compared with placebo in anemic patients receiving chemotherapy. J Clin Oncol 2005;23:2606-2617.

-25 Ludwig H, Evstatiev R, Kornek G, Aapro M, Bauernhofer T, Buxhofer-Ausch V, Fridrik M, Geissler D, Geissler K, Gisslinger H, Koller E, Kopetzky G, Lang A, Rumpold H, Steurer M, Kamali H, Link H: Iron metabolism and iron supplementation in cancer patients. Wien Klin Wochenschr 2015;127:907-919.

26 Wissenschaftlicher Beirat der Bundesärztekammer: Querschnitts-Leitlinien (BÄK) zur Therapie mit Blutkomponenten und Plasmaderivaten, ed 4. Berlin, Bundesärztekammer, 2014, pp 1-392. www.bundesaerztekammer.de/downloads/QLL_Haemotherapie_2014.pdf.

27 Aapro M, Beguin Y, Bokemeyer C, Dicato M, Gascon P, Glaspy J, Hofmann A, Link H, Littlewood T, Ludwig H, Osterborg A, Pronzato P, Santini V, Schrijvers D, Stauder R, Jordan K, Herrstedt J; ESMO Guidelines Committee: Management of anaemia and iron deficiency in patients with cancer: ESMO clinical practice guidelines. Ann Oncol 2018;29:iv96iv110.
28 Welsh L, Panek R, Riddell A, Wong K, Leach MO, Tavassoli M, Rahman D, Schmidt M, Hurley T, Grove L, Richards T, Koh D-M, Nutting C, Harrington K, Newbold K, Bhide $S$ : Blood transfusion during radical chemoradiotherapy does not reduce tumour hypoxia in squamous cell cancer of the head and neck. Br J Cancer 2016;116:28.

29 Meybohm P, Herrmann E, Steinbicker AU, Wittmann M, Gruenewald M, Fischer D, Baumgarten G, Renner J, Van Aken HK, Weber CF, Mueller MM, Geisen C, Rey J, Bon D, Hintereder G, Choorapoikayil S, Oldenburg J, Brockmann C, Geissler RG, Seifried E, Zacharowski $\mathrm{K}$ : Patient blood management is associated with a substantial reduction of red blood cell utilization and safe for patient's outcome: a prospective, multicenter cohort study with a noninferiority design. Ann Surg 2016;264:203-211.

30 Gombotz H, Hofmann A, Nørgaard A, Kastner P: Supporting Patient Blood Management $(\mathrm{PBM})$ in the EU - a Practical Implementation Guide for Hospitals. Luxembourg, Publications Office of the European Union, 2017. https://publications.europa.eu/en/publication-detail/-/publication/93e1bbbf-1a8b11e7-808e-01aa75ed71a1/language-en.
1 Carson JL, Stanworth SJ, Roubinian N, Fergusson DA, Triulzi D, Doree C, Hebert PC: Transfusion thresholds and other strategies for guiding allogeneic red blood cell transfusion. Cochrane Database Syst Rev 2016;(10):CD002042.

32 Aapro M, Moebus V, Nitz U, O’Shaughnessy J, Pronzato P, Untch M, Tomita D, Bohac C, Leyland-Jones B: Safety and efficacy outcomes with erythropoiesis-stimulating agents in patients with breast cancer: a meta-analysis. Ann Oncol 2015;26:688-695.

33 Leyland-Jones B, Bondarenko I, Nemsadze G, Smirnov V, Litvin I, Kokhreidze I, Abshilava L, Janjalia M, Li R, Lakshmaiah KC, Samkharadze B, Tarasova O, Mohapatra RK, Sparyk Y, Polenkov S, Vladimirov V, Xiu L, Zhu E, Kimelblatt B, Deprince K, Safonov I, Bowers $\mathrm{P}$, Vercammen E: A randomized, open-label, multicenter, phase III study of epoetin alfa versus best standard of care in anemic patients with metastatic breast cancer receiving standard chemotherapy. J Clin Oncol 2016; 34:1197-1207.

34 Aapro M, Osterborg A, Gascon P, Ludwig H, Beguin Y: Prevalence and management of cancer-related anaemia, iron deficiency and the specific role of i.v. iron. Ann Oncol 2012; 23:1954-1962. 